\title{
Russian political discourse-problems of interaction between government and society
}

\author{
L. G. Titova ${ }^{1}$, A. V. Uryadova ${ }^{1}$, S. A. Baburkin²
}

1P. G. Demidov Yaroslavl State University, 14 Sovetskaya str., Yaroslavl 150003, Russian Federation

2Yaroslavl State Pedagogical University named after K. D. Ushinsky, 108/1 Respublikanskaya str., Yaroslavl 150000, Russian Federation

DOI: $10.18255 / 2412-6519-2020-4-346-357$

Research Article

Full text in Russian

The article deals with the issues of modern Russian political discourse - the interaction of power and society, political communication, the influence of power through the spoken and written word on the mass consciousness. The significance of the problem in modern society is associated with the expansion of the political space through multi-sided political communication, the introduction of new subjects in the political polylogue, the dissemination of information flows that are exchanged by participants in the political process and which are not always adequately perceived and processed by them, which creates opportunities for purposeful management of people's behavior. In Russian political practice, this has been noted in various forms of controlled protest. Media texts, the interpretation of written texts in their variety of genres, the ability to persuade in oral speeches, the use of political terms, informal words and expressions, slang, depending on the audience and the goals set by the speakers, are becoming more and more common forms of influence. Modern political discourse is shown as existing outside of the moral requirements and restrictions imposed by the authorities, who pursue the main goal of self - preservation and selfrestraint, and use all methods of manipulation for this purpose, creating a pseudo-reality. This is especially significant in times of political crises, when power structures and leaders begin to reveal their failure, inability to make adequate political decisions, compensating them with various technologies of zombie population. Channels of influence are the media, which in the conditions of the information society turn into another power institution. Manipulative influence of the word can be neutralized in the dialogue between the government and society, which implies a high level of political culture of the elite and citizens.

Keywords: text; dialog; speech. political discourse; interpretation; manipulation; genre; pseudo-reality

\section{INFORMATION ABOUT THE AUTHORS}

$$
\begin{array}{c|l}
\text { Titiva, Lyudmila G. } & \begin{array}{l}
\text { E-mail: titovafspn@mail.ru } \\
\text { Doc. Sc. (Politics), Professor }
\end{array} \\
\text { Uryadova, Anna V. } & \begin{array}{l}
\text { E-mail: uryadovaanna@gmail.com } \\
\text { Doc. Sc. (History), Professor }
\end{array} \\
\text { Baburkin, Sergey A. } & \begin{array}{l}
\text { E-mail: baburkin@mail.ru } \\
\text { Doc. Sc. (Politics), Professor }
\end{array}
\end{array}
$$

For citation: Titova L. G., Uryadova A. V., Baburkin S. A. Russian political discourse-problems of interaction between government and society // Social'nye i gumanitarnye znanija. 2020. Vol. 6, No 4. P. 346-357. (in Russ.)

(C) Titova L. G., Uryadova A. V., Baburkin S. A., 2020

This is an open access article under the CC BY license (https://creativecommons.org/licenses/by/4.0/) 


\title{
Российский политический дискурс - проблемы взаимодействия власти и общества
}

\author{
Л. Г. Титова ${ }^{1}$, А. В. Урядова ${ }^{1}$ С. А. Бабуркин ${ }^{2}$ \\ 1ЯрГУ, ул. Советская, 14, Ярославль, 150003, Российская Федерация \\ 2ЯГПУ им. К. Д. Ушинского, ул. Республиканская, 108/1, Ярославль, 150000, Российская Федерация
}

DOI: $10.18255 / 2412-6519-2020-4-346-357$

УДК 323

Научная статья

Полный текст на русском языке

В статье рассматриваются вопросы современного российского политического дискурса - взаимодействия власти и общества, политической коммуникации, влияния власти посредством устного и письменного слова на массовое сознание. Значимость проблемы в условиях современного общества связана с расширением политического пространства за счет многосторонней политической коммуникации, введения новых субъектов в политический полилог, распространения потоков информации, которыми обмениваются участники политического процесса и которые не всегда адекватно воспринимаются и перерабатываются ими, что создает возможности целенаправленного управления поведением людей. В российской политической практике это отмечено в различных формах управляемого протеста. Все более распространенными способами влияния становятся медиатексты, интерпретации письменных текстов в их жанровом многообразии, умение убеждать в устных выступлениях, использование политических терминов, неформальных слов и выражений, сленга в зависимости от аудитории и целей, которые ставят перед собой выступающие. Современный политический дискурс показан как существующий вне нравственных требований и ограничений со стороны властных субъектов, преследующих главную цель - самосохранения и самоудержания - и использующих для этого все методы манипулирования с созданием псевдо-реальности. Это особенно значимо в периоды политических кризисов, когда властные структуры и лидеры начинают обнаруживать свою несостоятельность, неспособность к принятию адекватных политических решений, компенсируя их различными технологиями зомбирования населения. Каналами воздействия являются СМИ, которые в условиях информационного общества превращаются в еще один властный институт. Манипулятивное воздействие словом может быть нейтрализовано в диалоге между властью и обществом, что предполагает высокий уровень политической культуры элиты и граждан.

Ключевые слова: текст; диалог; речь; политический дискурс; интерпретация; манипулирование; жанр; псевдо-реальность

ИНФОРМАЦИЯ ОБ АВТОРАХ

\begin{tabular}{r|l} 
Титова, Людмила Григорьевна & $\begin{array}{l}\text { E-mail: titovafspn@mail.ru } \\
\text { Доктор политических наук, профессор }\end{array}$ \\
Урядова, Анна Владимировна & $\begin{array}{l}\text { E-mail: uryadovaanna@gmail.com } \\
\text { Доктор исторических наук, професcop }\end{array}$ \\
Бабуркин, Сергей Александрович & $\begin{array}{l}\text { E-mail: baburkin@mail.ru } \\
\text { Доктор политических наук, профессор }\end{array}$
\end{tabular}

Для цитирования: Титова Л. Г., Урядова А. В., Бабуркин С. А. Российский политический дискурс проблемы взаимодействия власти и общества // Социальные и гуманитарные знания. 2020. Том 6, № 4. C. 346-357.

(C) Титова Л. Г., Урядова А. В., Бабуркин С.А., 2020

Статья открытого доступа под лицензией СС BY (https://creativecommons.org/licenses/by/4.0/) 
Современный политический процесс является дискуссионным явлением в силу неоднозначности для населения принимаемых политических решений, противоположных восприятий мира политики разными социальными группами, специфики индивидуального восприятия, слабости обратных связей между властью и обществом, различных толкований используемых понятий и политических символов. Общество углубляющейся дифференциации постепенно превращается в гигантский дискуссионный клуб, частично инициированный властью, частично - лицами с корпоративными или частными интересами.

Предоставляемые возможности, как технические, так и правовые, расширяют участие граждан в обсуждении возникающих проблем.

Реалии современной политики таковы, что имеющиеся подходы к происходящему требуют не только пересмотра многих методов анализа, но и корректировки понятийного аппарата политической науки, уточнения содержания понятий, которые традиционно составляют основу политических наук, что и происходит в многочисленных дискуссиях, которые ведутся не только в научной литературе, на научных форумах, но и в средствах массовой информации. Дискурсными являются концепты политических систем и политического режима, современных демократий, протестных движений, частные проблемы выборов, войн в различных регионах планеты и т. д.

Имеющаяся возможность свободного обсуждения наиболее острых вопросов внутренней и внешней политики, несомненно, важнейшее достижение демократии. Практически, все вопросы современной политики находятся в дискуссионном поле, вовлекая в него не только экспертов и специалистов, но и рядовых граждан, что создает определенные проблемы для выявления подлинного значения многих понятий и, в свою очередь, для более точных оценок событий: за пределами научных споров - игра словами, подмена понятий, что неизбежно при произвольном обращении неспециалистов с терминологий. Создается прецедент, нуждающийся в усилении научного подхода к выявлению сущности обсуждаемых явлений.

В настоящее время не существует единой точки зрения на содержание понятия «политический дискурс». Тем не менее существующие концепции группируются в ряд общих позиций. Во-первых, к политическому дискурсу относится дискуссионная часть политического процесса - обсуждаемые на различных дискуссионных площадках спорные вопросы современной политики. Во-вторых, политический дискурс - выявляемые в научных дискуссиях различные точки зрения на содержание политологических понятий, выстраивание понятийного аппарата политологии, адекватно раскрывающего проблемные стороны современной политики. Третьей трактовкой политического дискурса является коммуникационная деятельность политических акторов, представителей властных структур, стремящихся определенным образом формировать общественное сознание с целью подчинения либо убеждения в правильности принимаемых решений. Наконец, дискурс рассматривается как речевая деятельность, передача в символической форме идей и ценностей, характеризующая политический процесс в данной стране и данный период времени. Названные подходы находят отражение в определениях, формулируемых рядом авторов, которые обращают 
внимание на многозначность данного явления, связи со средой, в которой производится речевое действие, мышлением лидеров и массы.

Политический дискурс представлен в виде общения на уровне политических институтов, внеличностного общения, обладающего собственным терминологическим языком в рамках представлений о политике как речевом действии [1]. Современный постмодернизм трактует дискурс как форму социальных взаимодействий, которые отличаются полифоничностью, многоаспектностью, спонтанностью и зависят от социальной среды [2]. Дискурс связывают с особенностями мышления политиков, о которых судят по их языку, а также с особенностями массового сознания, проявляющимися в текстах средств массовой информации [3, с. 56]

Понимание политического дискурса требует, как показывает качественный анализ проблемы, привлечения широкого круга специалистов для применения комплексного подхода, включающего выводы теорий информационного общества, теории коммуникаций и теории конфликтов, а также новейших достижений современной лингвистики. Существенный вклад в понимание сущности политического дискурса вносит философия, эволюция речевой и коммуникативной практики взаимодействия общества и власти прослеживается исторической наукой, правовые аспекты этого взаимодействия на институциональном уровне - теорией государств и права.

Для научного сообщества методологически важно уяснить значение политических терминов в постоянно расширяющемся понятийном аппарате политической науки. Непрекращающиеся дискуссии по поводу современных понятий политического процесса отражают возникающий комплекс проблем на каждом политическом этапе [4].

Мир политики - мир политических коммуникаций в виде речевого общения политических акторов, форм и технологий этого общения, в котором либо достигается некоторое понимание происходящего, либо властвующие субъекты пытаются убедить население в правильности проводимой политики.

Проблемой является владение речевой практикой, умением убеждать и внушать веру в эффективность существующей власти массам. Однако широкие возможности информационного общества позволяют включать новые технологии политического влияния через интернет и телевидение. Теория информационного общества рассматривает его как систему проникновения информационных технологий во все сферы его существования, в том числе и в сферу политики, где многократно возрастают возможности получения нового знания, использования объяснительного принципа в трактовке политических явлений, но вместе с тем создаются практически безграничные возможности воздействия на массовое сознание, что активно и эксплуатируется властью.

Относительно новой отраслью науки является политическая лингвистика, в предметное поле которой входят многочисленные дискуссии по вопросам изучения политического языка как знаковой системы, политических символов, устной и письменной политической речи. Например, эти дискуссии ведутся в непостоянной рубрике «Дискуссии» журнала «Политическая лингвистика», 
где обсуждаются часто прямо противоположные взгляды на проблему политического языка. Изучение собственно лингвистической основы языка, механизма его действия расширяется за счет анализа внеязыковых факторов.

Значимая составляющая политического дискурса - правовое обеспечение политической коммуникации в условиях информационного общества. Связи и отношения, формируемые в информационном пространстве, могут создаваться как правовые, так и вне права, что ограничивает получение достоверной информации, противоречит принципам национальной безопасности страны и свободного, устойчивого, безопасного взаимодействия граждан [5]. Обеспечение прав граждан на доступ к информации, свободного выбора средств получения знаний при работе с информацией - принципы, выдвинутые в Стратегии развития информационного общества Российской Федерации на 2017-2030 годы», принятой Указом Президента РФ в 2017 годуํㅡㄹ российском нормотворчестве сделано многое для обеспечения передачи новых знаний, использования новых технологий получения и распространения информации, в том числе и политической. Однако требуется еще длительный переходный адаптационный период для привыкания населения к действию в информационном пространстве [6, c. 74], к соблюдению законов всеми, в том числе и самой властью. Это период активного обсуждения в научном сообществе, специалистами в области юриспруденции вопросов обновления законодательной системы применительно к новым условиям информационного общества.

Акцентирование значений, интерпретация понятий в медиатекстах становятся новой политической реальностью, формируемой в сознании граждан, этот социальный и нравственный аспект политической коммуникации - результат взаимной ответственности ученых и политиков: первых - за точность определения, вторых - за адекватное использование-объяснение политических событий. Объективная трудность заключается в многозначности слова, в способности и готовности слушателя (читателя, зрителя) воспринимать сказанное. Вместе с тем интересы субъекта речи, его целевые установки, политические предпочтения, политический статус, ситуативная востребованность открывают широкие возможности для манипулирования словом, влияния на сознание и поведение граждан. Поскольку речевая деятельность занимает немалое место в действиях политика, важно, чтобы она не превращалась в бесконечный монолог власти, а уступала место ее диалогу с обществом в различных ситуациях современной политической жизни. Задачи, технологии, виды диалога все чаще становятся предметом изучения в рамках исследования политических коммуникаций. Значительное внимание уделяется проблемам политического дискурса в различных формах: от медиатекстов до общественно-политических дебатов и дискуссий (в работах Е. И. Шейгала, М. А. Козюлиной, Ю. Ю. Суханова, В. З. Демьянкова и других [7].

Многочисленные примеры свидетельствуют о распространенности политических дискуссий на различные темы и в различных форматах: ток-шоу (Вечер

\footnotetext{
1 Указ Президента РФ от 09.05.2017 № 203 «О Стратегии развития информационного общества в Российской Федерации на 2017-2030 годы». URL: http://publication.pravo.gov.ru/Document/View/0001201705100002. Официальный интернет-портал правовой информации (дата обращения: 15.11.2020)
} 
с Владимиром Соловьевым, 60 минут, Время покажет, Место встречи, Право голоса, Право знать), экспертные дискуссии, клубы, цикличные дискуссии. Технологические возможности СМИ, интернета позволяют непосредственно откликаться на актуальнейшие проблемы дня. В дискуссионных медиаматериалах обсуждаются политические решения, вызовы и риски развития мира в условиях глобализации, будущее человечества.

На различных образовательных площадках, в средствах массовой информации, на научных конференциях, политических форумах обсуждается характер проведения политических диспутов, профессионализм ведущих, искусство спора и культура политического общения в целом. Последнее тем важнее, что плодотворный по сути и незаменимый по содержанию способ общения с аудиторией, будь то депутатский корпус, слушатели на массовом митинге или многочисленные телевизионные зрители, нередко превращается в закамуфлированное или откровенное давление на собеседника, вольное обращение с фактами, субъективную интерпретацию событий. Грубость, применение неформальной лексики, употребление слов, которые раньше назывались непечатными, становятся правилом в российских политических телевизионных выступлениях и передачах. Типичный пример - истеричные и неадекватные выкрики в телестудии телеведущего Владимира Соловьева, который почти не утруждает себя аргументацией в споре, обращается к одним и тем же экспертам, некорректным поведением намеренно взвинчивает атмосферу в студии.

Способ конфликтного ведения диалога и полилога нередко выбирается для обнажения противоречий, обострения проблемы, доведения до крайности позиций участников, однако «за кадром» остаются все возможные позитивные решения, сохраняется впечатление несправедливости и безнравственности мира, в котором вынужден жить человек. Это, кстати, в последние годы становится общим тоном всех российских политических шоу. В общественном сознании формируется представление о порочности мира в целом, что прямо или косвенно оправдывает все просчеты политического управления. Другой заданностью становится обратное стремление сгладить противоречия, вопреки здравому смыслу утверждать исключительно позитивный характер российской политики, ее приоритет в мире. И, наконец, демонстрируется стремление создать «объективную» картину происходящего, для чего приглашаются «независимые» эксперты, озвучивается медиативная точка зрения, якобы примиряющая конфликтующие стороны и в то же время претендующая на истину в последней инстанции, утверждение заранее определенной позиции.

В этом плане российские политические дебаты существенно трансформировались по сравнению с периодом конца 80-х - начала 90-х годов. Они стали реальностью, когда в условиях перестройки началось активное обсуждение всех насущных вопросов российского прошлого, настоящее и будущего.

Поспешно осваивался зарубежный опыт (Попперовские дебаты в образовании, например), велись многочисленные, транслируемые по радио и телевидению, дискуссии в Верховном совете СССР, на стадионах решали, быть или не быть марксизму, в заводских цехах - смертной казни, на телемостах - нашим новым отношениям с Западом, в «толстых» журналах - частной собственности, в армии 
- службе по контракту. В печати шли разоблачения коррумпированной партийной и советской верхушек, гремело «узбекское дело», разоблачения Гдляна и Иванова - страна на десятилетие превратилась в огромную дискуссионную площадку, на которой в лихорадочном увлечении объявленной гласностью восполнялся дефицит свободного устного и печатного слова. С очевидностью явили силу политический диспут, диалог, спор, дискуссия. И с такой же очевидностью становилось ясно, что новой политической элите придется учиться умению политического общения, политической науке - осваивать политическую лексику, а политическим ораторам - пользоваться политическим словом. Несмотря на то, что все эти искусства были известны человечеству издавна, российские политики «новой волны» вынуждены были считаться с необходимостью овладения демократическим языком политической коммуникации, разыгрывая близость к народу в поведении, выступлениях, позже - во всемирной сети.

В истории политики речевое действие имело не менее важное значение, чем само политическое действие. Политика в античности выражалась прежде всего в слове, ораторское искусство было средством и убеждения оппонента, и поражения противника, и привлечения единомышленников. Споря с софистами, Платон, Сократ, Аристотель подчеркивали, что главным для оратора является не форма речи, а поиск истины [8]. Марк Туллий Цицерон уверял, что красноречие - главное орудие в руках государства.

Традиции рассматривать дискурс как обеспечение власти сохраняются и в настоящее время [9, с. 14]. Вместе с тем дискурс предполагает взаимодействие участников коммуникативного процесса, в котором второй стороной выступает общество; для него дискурс - форма политического участия, где транслируются не только определенные потребности, но и то или иное отношение к власти. Власть «обеспечивает себя», то есть словесно легитимизируется, внушая веру в свою эффективность, особенно в случаях нерезультативных политических решений.

Воздействие слова на аудиторию привлекало внимание исследователей различных эпох, начиная с античности, когда обучение искусству речи приобретало значимость наравне с философскими трактатами и являлось важной составляющей деятельности политика. Было замечено, что политическое слово в зависимости от культуры и целей говорящего может обладать силой воздействия, равной, а нередко большей, чем принуждение и насилие, всегда сопровождающие власть. Используя его для убеждения слушателя (читателя, зрителя), античные авторы проводили различие между допустимыми и недопустимыми методами, между манипулированием и аргументированным убеждением. Корректируя учение софистов, Аристотель утверждал, что убеждать необходимо только допустимыми средствами, опираясь на логику, этику и эмоцию (логос, этос и пафос), учитывая особенности аудитории, самой речи, используя характер говорящего, обращаясь к тому или иному настроению слушателей [9]. Словесное воздействие - искусство оратора, который должен убедить людей в своих нравственных качествах, вызвать у них определенное настроение, заставить поверить в верность сказанного. Истина и нравственность, таким образом, считались производным от искусства говорящего, его способности доказывать то, что он считает верным и чему начинают верить слушатели. Политическая речь - 
совещательная, касается таких предметов, которые требуют реакции слушателя, но в которой нет задачи установить истину или справедливость, а лишь «склонить или отклонить» слушателя в процессе речи. Эта особенность политической речи, отмеченная античным автором, свидетельствует о том, что нравственность оратора воспринималась в его стремлении донести до слушателя свою мысль, свою идею, о правильности которой слушатель будет судить и делать выводы сам. Важен культурный контекст, в котором встречаются оратор и слушатели: если он совпадает, оратор выполняет свою задачу, а слушатель свободен в выборе решения.

Отточенное в Древнем Риме греческое искусство устного политического выступления постепенно уступало место письменной речи, распространившейся с появлением книгопечатанья.

Письменные политические тексты длительное время сохраняли сакральный характер, оставаясь привилегией избранных, писались языком, доступным немногим, часто содержали смысл туманный, неясный для большинства населения, неграмотного и далекого от политики. С самого начала появления письменных материалов на их содержание влияли не только языковые, но и внеязыковые факторы: развитость информационных технологий, социальное положение автора и реципиента, политическая культура обеих сторон, условия восприятия текстов, развитость каналов их распространения, целевые установки политических субъектов, их мыслительный мир, характер власти и политического режима. Внеязыковые факторы выполняли функцию выбора языка, жанра политического текста, его содержания [10, с.32], отбор которых позволяет устанавливать связь между политиком и реципиентом - адресатом политического обращения.

Современный политический текст российских политиков в разных жанрах и модификациях представляет знаковую систему двойных стандартов, скрывающих, нередко шифрующих их подлинные мысли и замыслы. Отражаясь в строе речи, трактовка политических событий создает некую псевдо-реальность, многократно искажаемую, как изображение в кривом зеркале. Используется многозначность слова, оттенки интонации, сопровождающие жесты - вербальные и невербальные способы передачи информации с тем, чтобы вызвать у адресата определенное состояние, необходимое в данной ситуации.

Жанровое многообразие политических текстов - свидетельство множественных способов достижения, сохранения и удержания власти в ходе политической коммуникации. В отличие от речевого общения они представляют собой письменный источник, содержание которого определено необходимостью выстраивания длительного взаимодействия с аудиторией в той или иной политической ситуации и зависит от особенностей письменной речи. Наиболее распространенными жанрами политической письменной речи являются официальные документы (конституции, приказы, указы, программы политических партий), письменные обращения, агитационные материалы, записанные и опубликованные интервью, научные статьи. Жанры, связанные с борьбой за власть, избирательными кампаниями, созданием политического имиджа, протестными движениями, обладают более широким арсеналом языковых средств, нежели официальные документы, имеющие строго фиксированные языковые нормы. 
Качество политического текста определяется степенью его институционализации и структурированности, использованием тропов, пословиц, поговорок, идиоматических выражений. Задача семантических средств - вызвать определенное эмоциональное состояние воспринимающего, отрицательные или положительные эмоции. Отрицательные - чувство негодования, агрессии, страха при акцентировании внимания на несправедливости происходящего, нарушении прав, угрозах извне или идущих от внешних и внутренних врагов. Положительное эмоциональное состояние должно вызвать определенное лицо (кандидат на какую-то должность, политический лидер, занимающий ведущие позиции, лидер партии, представитель администрации), события (политические праздники, борьба с негативными явлениями, подписание договоров, которые преподносятся общественному мнению как значимые явления для жизни страны). Для создания иллюзии сопричастности и взаимодействия используются такие обороты, как: «вы согласитесь, что...», «как вы уже поняли», «мы с вами должны считаться с тем, что...», и другие, им подобные.

Политический дискурс дает возможность рассмотреть влияние вербальных средств на массовое сознание. Современный диалог российской власти с обществом представляет вялотекущую критику со стороны оппозиции, заученноповторяющуюся лексику официальных представителей власти и сленги протестных движений. Строй речи российских политиков, смысл, который они вкладывают в отдельные слова и выражения, заслуживает отдельного исследования, однако достаточно ознакомиться с реакцией представителей власти на происходящие события, чтобы понять: разрыв между населением и властью углубляется. Создаваемая с начала 2000-х вертикаль власти укрепилась в общественном сознании как неэффективная. Более одной трети опрошенных Левада-Центром считают ее средоточием коррупции, более половины убеждены, что руководство озабочено сохранением и укреплением власти, заботится о собственных интереcax, a не о благе страны [11]. Социологические опросы показывают, что из-за невыполняемых обещаний недоверие граждан к власти растет, их недовольство усиливается. Последствиями становятся акции протеста, на которые власть реагирует более болезненно, чем во время выступлений 2011-2012 гг., о чем свидетельствуют действия полиции во время июльских-августовских событий 2019 года. Наряду с разгоном демонстрантов дубинками, многочисленными арестами и обысками в офисах и домах лидеров и организаторов акций, официальные лица обращаются к проверенной технологии риторического воздействия при освещении событий на телевизионных каналах, пуская в ход богатый арсенал информационных приемов: переключение внимания на международные события, катастрофы внутри страны и за рубежом, обрыв текста высказываний. Политические телевизионные шоу демонстрируют наступательный метод ведения диалога, эпатаж, подавление собеседника. При отсутствии общенациональной идеи все более обнаруживает себя стремление сделать слово, язык, речь интегрирующими факторами нации.

Речь не только явление лингвистическое, она встроена в общий культурный код нации, меняясь вместе со временем, с изменением в системе ценностей, «обслуживая» потребности участников политических событий. 
Если охватить в целом лингвистический строй российского политического языка, ему присуще свойство, отмеченное братьями Вайнерами: душу в нем заменяют символы: символы чувств - радости, страха, отчаяния, сочувствия - которые в разнообразном виде демонстрируется на экранах телевидения, в интервью, в печати, в интернете. Свойство языка создавать иную реальность в мышлении воспринимающего в зависимости от его знаний, опыта, чувств, настроения используется для формирования мировоззрения, политических установок и соответствующего поведения. Все вместе взятое не просто направлено на формирование «усредненного» сознания, ориентированного на заданные ценности, оно исподволь подрывает основы культуры и нравственности, уничтожает нормы, веками апробированные в человеческих отношениях. Усилиями политтехнологов и СМИ играется спектакль, главным постановщиком которого является власть. В ее кулуарах пишется сценарий, обозначающий ключевые моменты, кнопки, на которые следует нажимать, чтобы снизить накал социального напряжения и решить сверхзадачу - добиться легитимизации действий власти путем создания видимости социального и политического партнерства. Как следствие - создание виртуальной реальности, лже-реальности, в которой человеку предлагается такое видение события, которое мыслит постановщик.

Исследователи протестных движений подчеркивают стремление официальных лиц закамуфлировать реальные события в массовом сознании, ретушировать происходящее [12] с тем, чтобы скрыть собственные просчеты, сгладить проблемы и создать видимость контроля над протестующими. Анализируя российские протестные выступления, мы можем констатировать аналогичную реакцию российского руководства, которое к томуже продолжает использовать образ внешнего врага и ищет след западных влияний на российский протест.

Речь российских политиков эволюционировала от официально-нейтральной, научно выверенной, риторически грамотной к обыденной лексике, просторечным словам и выражениям. Если речь М. С. Горбачева при вручении ему Нобелевской премии мира представляет собой образец риторики - в структурной организации текста, в построении фразы, ритмике и смысловом выражении - то следующая когорта политиков уже более свободна в словах и выражениях, их речи лишены академизма, что согласуется с образом «своего парня» и свидетельствует об эволюции языка политики от официально-нейтрального, научно выверенного, терминологического к эмоционально-агитационному. При всей присущей ей некоторой стилевой индивидуальности официальная речь политиков обезличена, повторяема, в ней явно прослеживается стремление увести сознание слушателей от реальности, заменить ее псевдо-реальностью путем подмены содержания, искажения смысла, стереотипичности, умиротворяющих фраз. Это еще оказывает воздействие на значительную часть населения, однако массовые протесты лета 2019 года показали, что, несмотря на стремление официальной власти «заговорить» население, молодежь выходит из-под ее влияния. Не случайно большей популярностью у нее пользуется В. В. Жириновский с его сленгом и имиджем эпатажного политика.

Молодежные акции протеста при всей неоднозначности способов действий - сигнал серьезного неблагополучия в государстве. Ее недовольство и воз- 
мущение, выражающиеся, в том числе, в речи, в нарушении норм политкорректности, - свидетельство прихода в политику иного поколения с его ценностями, представлениями, культурой.

Политический дискурс в России - явление относительно новое, отличается разнообразием, далеко от академизма, активно используется как средство легитимизации власти путем манипулирования сознанием и поведением людей различных социальных групп. В результате проведенного анализа авторы предлагают:

- использовать данные мониторинга отношения населения к принимаемым политическим решениям для налаживания диалога с гражданами на региональном и местном уровне;

- активно использовать академическую форму обсуждения понятийного аппарата политической науки, включая вопросы методологии политического анализа в программы научных конференций, круглых столов и других научных форумов;

- шире вовлекать молодых специалистов в научные дискуссии;

- расширять правовую основу диалога между представителями власти и гражданского общества;

- использовать платформу гражданских дискуссий для обсуждения приоритетных проблем политического процесса при участии политических партий и общественных организаций;

- вводить курсы риторики для подготовки политологов, обращаясь к историческому опыту риторов от античности до настоящего времени.

\section{Ссылки / References}

1. Синеокая Н. А. Характеристика политического дискурса // Современные проблемы науки и образования. 2012. № 6. URL: http://scienceeducation.ru/ru/article/view?id=7695 (дата обращения: 10.11.2020).

2. Кузнецова Н. В. Политический дискурс, обеспечивающий власть политической элиты // Политический дискурс в парадигме научных исследований. Сборник статей II международной научной конференции. Тюмень: Вектор Бук, 2015. C. 14-22.

3. Пилюгина Е. В. Дискурс в политике и политика как дискурс: Актуальные резонансы социального бытия постмодерна // Евразийский журнал региональных и политических исследований. Челябинск: Изд-во Челябинского государственного университета, 2013. № 23 (14). С. 42-48.

4. Романова Т. В. Современный политический дискурс: специфика и методика анализа // Respectus Philologicus. 2007. № 11. С. 56-67.

5. Медушевский А. Н. Глобализация и либеральная демократия. К промежуточным итогам дискуссии. 11.02.2019 // Фонд «Либеральная миссия». URL: http://liberal.ru/trends/globalizaciya-i-liberalnaya-demokratiya-k-promezhutochnymitogam-diskussii (дата обращения: 15.11.2020)

6. Рыбаков О. Ю. Приоритеты развития информационного общества в России: правовое обеспечение // Мониторинг правоприменения. 2017. № 3 (24). С. $71-76$. 
7. Суханов Ю. Ю. Политический дискурс как объект лингвистического анализа // Вестник РУДН. Серия: Теория языка. Семиотика. Семантика. 2018. Т. 9. № 1. C. 200-212.

8. Шевякова Е. А. Ораторское искусство античности // Бюллетень медицинских интернет-конференций. 2017. Т. 7. № 6. С. 851.

9. Аристотель. Поэтика. Риторика. СПб: Азбука, 2000. URL: http://masterslova.narod.ru/book/aristotel_poetika_ritorika.pdf (дата обращения: 15.11.2020).

10. Хун Лю. Особенности реализации политического дискурса в художественном тексте: постановка проблемы // Политическая лингвистика. 2017. № 3 (63). C. 31-41.

11. Сергеева Л. Населению надоела вертикаль власти // Ведомости. 09.02.2012. URL: https://www.vedomosti.ru/politics/articles/2012/02/09/vertikal_razlyubili (дата обращения: 15.11.2020).

12. Кучеренко К. В. Манипулятивное воздействие в испанском политическом дискурсе: слова-стереотипы, слова-смыслы, слова-слоганы // Вестник МГИМО. 2012. № 5. C. 255-259. 